\title{
Ultrasound-Guided Sacroiliac Joint Injection Technique
}

Dominic Harmon, MD, FCARCSI, and Michael O'Sullivan, MB, MRCS

From: Department of Anesthesia and Pain Medicine, Mid-Western Regional Hospital, Dooradoyle, Limerick, Ireland

Dr. Harmon and Mr. O’Sullivan are with the Department of Anesthesia and Pain Medicine, Mid-Western Regional Hospital, Dooradoyle, Limerick, Ireland

Address correspondence: Professor Dominic Harmon, 1 Department of Anesthesia and Pain Medicine, Mid-Western Regional Hospital, Dooradoyle, Limerick, Ireland

E-mail: dominic.harmon@hse.ie

Disclaimer: There was no external funding in the preparation of this manuscript. Conflict of interest: None.

Manuscript received: 01/14/2008 Revised version received: $04 / 23 / 2008$ Accepted for publication: $05 / 14 / 20008$

Free full manuscript: www.painphysicianjournal.com
We describe a case report and technique for using a portable ultrasound scanner and a curvilinear transducer (4-5MHz) (SonoSite Micromaxx SonoSite, Inc. 21919 30th Drive SE Bothwell W. A.) to guide sacroiliac joint (SIJ) injection.

A 42-year-old male presented with chronic lower back pain centered on his left SIJ. His pain averaged 7 out of 10 (numerical rating scale). For the ultrasound-guided SIJ injection the patient was placed in the prone position. The ultrasound transducer was oriented in a transverse orientation at the level of the sacral hiatus. Here the sacral cornuae were identified. Moving the transducer laterally from here, the lateral edge of the sacrum was identified. This bony edge was followed in a cephalad direction with the transducer maintained in a transverse orientation. A second bony contour, the ileum, was identified. The cleft between both bony contours represented the sacroiliac joint. This was found at $4.5 \mathrm{~cm}$ depth. Real-time imaging was used to direct a $22 \mathrm{G}$ spinal needle into the SIJ, where solution was injected under direct vision.

The patient's pain intensity decreased to a 2 out of 10 (numerical rating scale). Function improved and the patient was able to return to work. These improvements were maintained at 16 weeks. Ultrasound guidance does not expose patients and personnel to radiation and is readily accessible.

Ultrasound-guided SIJ injections may have particular applications in the management of chronic lower back pain in certain clinical scenarios (e.g. pregnancy). Future studies to demonstrate efficacy and reproducibility are needed.

Key words: Technique, visualization, real-time, ultrasound, sacroiliac joint.

Pain Physician 2008; 11:4:543-547

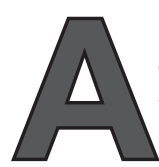

42-year-old male patient (BMI 25) presented with persistent, debilitating left-sided lower back pain. The onset of pain was associated with a road traffic accident 10 months previously. His pain averaged 7 out of 10 (numerical rating scale). The pain was centered on the left sacroiliac joint (SIJ), and was associated with tenderness to palpation in this region. The patient had positive left-sided sacroiliac joint provocation tests including distraction, thigh thrust, and sacral thrust (1). Neurological exam was normal. Magnetic resonance imaging (MRI) of the lumbar spine indicated mild degenerative change of 
the left SIJ.

Conservative measures of anti-inflammatory medications and physical therapy had failed to resolve symptoms. As a result the patient was unable to fulfill all of his work commitments. He had to opt for light duties and reduced hours in his work in the construction industry.

The patient consented to an ultrasound-guided left SIJ injection. He was placed in the prone position. A pillow was placed under the abdomen to straighten the lumbar lordosis. The operator and the ultrasound screen were positioned on the side to be injected. A low frequency $(4-5 \mathrm{MHz})$, curvilinear transducer (Sonosite ${ }$, Micromaxx, Bothwell, WA, USA) is felt to be optimal for the procedure.

The skin was disinfected with antiseptic solution and draped. The ultrasound transducer was inserted into a sterile sheath (CIVCO Medical Instruments, Kalona, IA, USA) containing ultrasound gel. A thin layer of sterile gel was placed between the draped ultrasound transducer and the skin.

At the level of the sacral hiatus, the ultrasound transducer was oriented in a transverse orientation (Fig. 1). Here the sacral cornuae were identified (Fig. 2). Moving the transducer laterally from here, the lateral edge of the sacrum was identified (Fig. 3). This bony edge was followed in a cephalad direction with the transducer maintained in a transverse orientation.
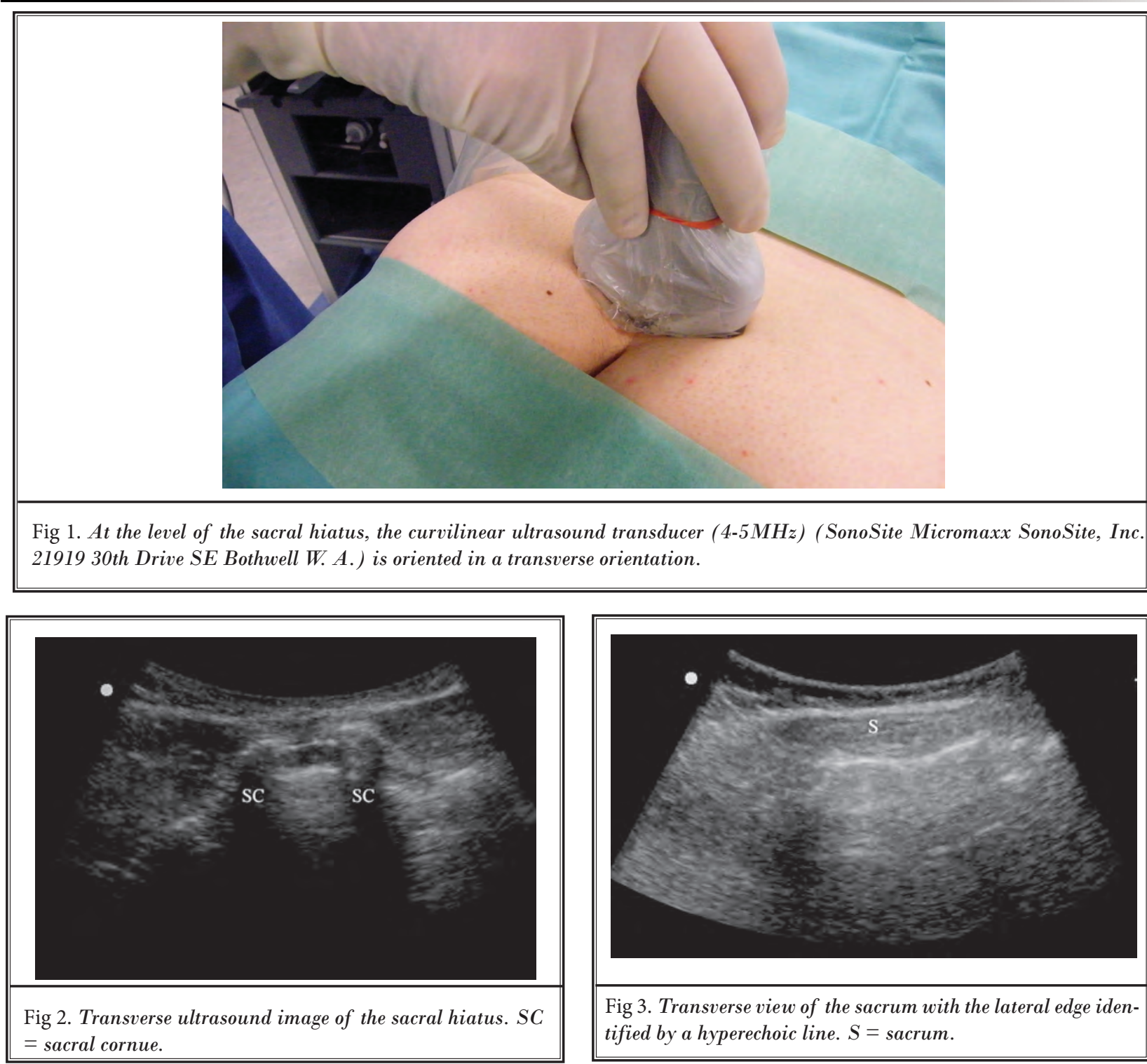

Fig 3. Transverse view of the sacrum with the lateral edge identified by a hyperechoic line. $S=$ sacrum. 
A second bony contour, the ileum, was identified. The cleft between both bony contours represents the posterior aspect of the sacroiliac joint (Fig. 4). The sacroiliac joint was identified at $4.5 \mathrm{~cm}$ depth. At this stage, tilting the transducer in a caudal direction identified the posterior caudad SIJ, the portion of the joint into which the injection should be performed. Tilting the transducer in a cephalad direction identified the posterior cephald part of the SIJ (Fig. 5).

A skin wheal of local anesthetic was raised at the medial edge of the transducer. A 22-gauge cuttingedge spinal needle (Becton Dickinson S.A, Madrid, Spain) was inserted in line with the transducer (Fig. 6). The needle was advanced in a medial to lateral direction, under direct vision, until the needle was positioned in the SIJ (Fig. 7). Local anesthetic and steroid solution mixture was injected. If the injection is extraarticular, injectate (hyperechoic solution as it contains particulate steroid) can be seen spreading medially over the sacrum. In this patient we did not correlate that the needle was intraarticular with appropriate contrast spread with fluoroscopy. Both techniques were used simultaneous in the early learning curve. The patient's pain intensity decreased to 2 out of 10 (numerical rating scale). The patient was able to make a gradual return to physical past-times such as running. The patient also returned to regular work duties. These improvements were maintained at 16 weeks.

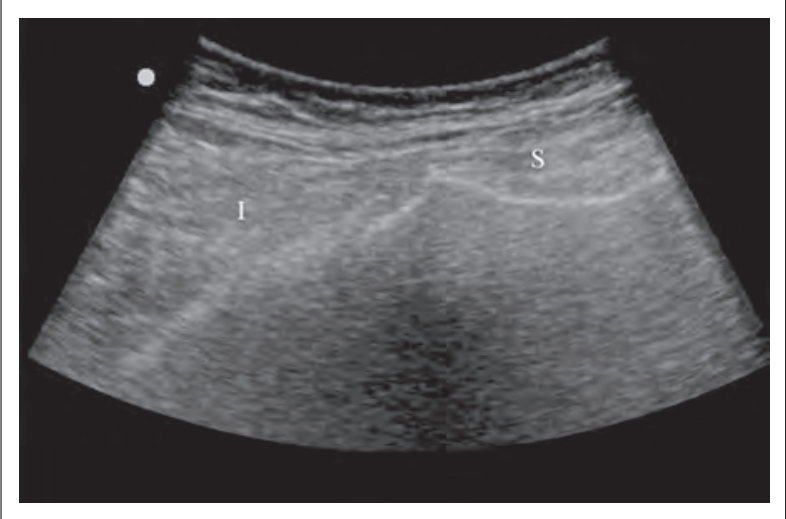

Fig 4. Transverse view of the posterior caudad sacroiliac joint. $I=$ ileum; $S=$ sacrum.

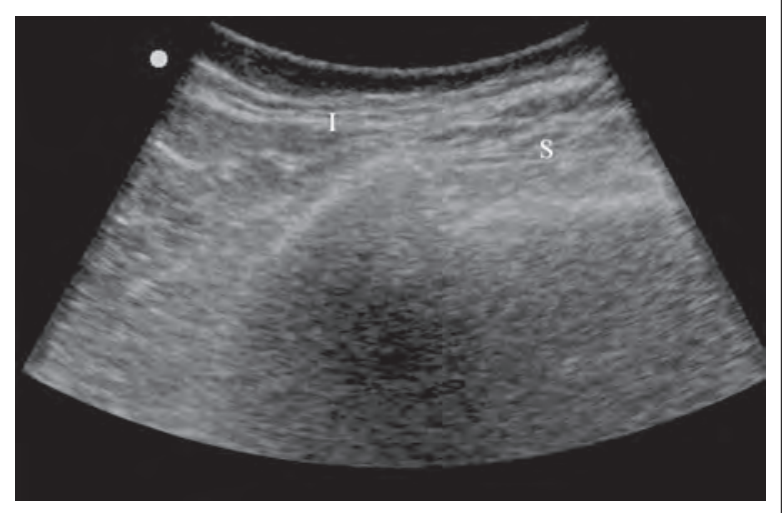

Fig 5. Transverse view of the posterior cephalad sacroiliac joint. $I=$ ileum; $S=$ sacrum.

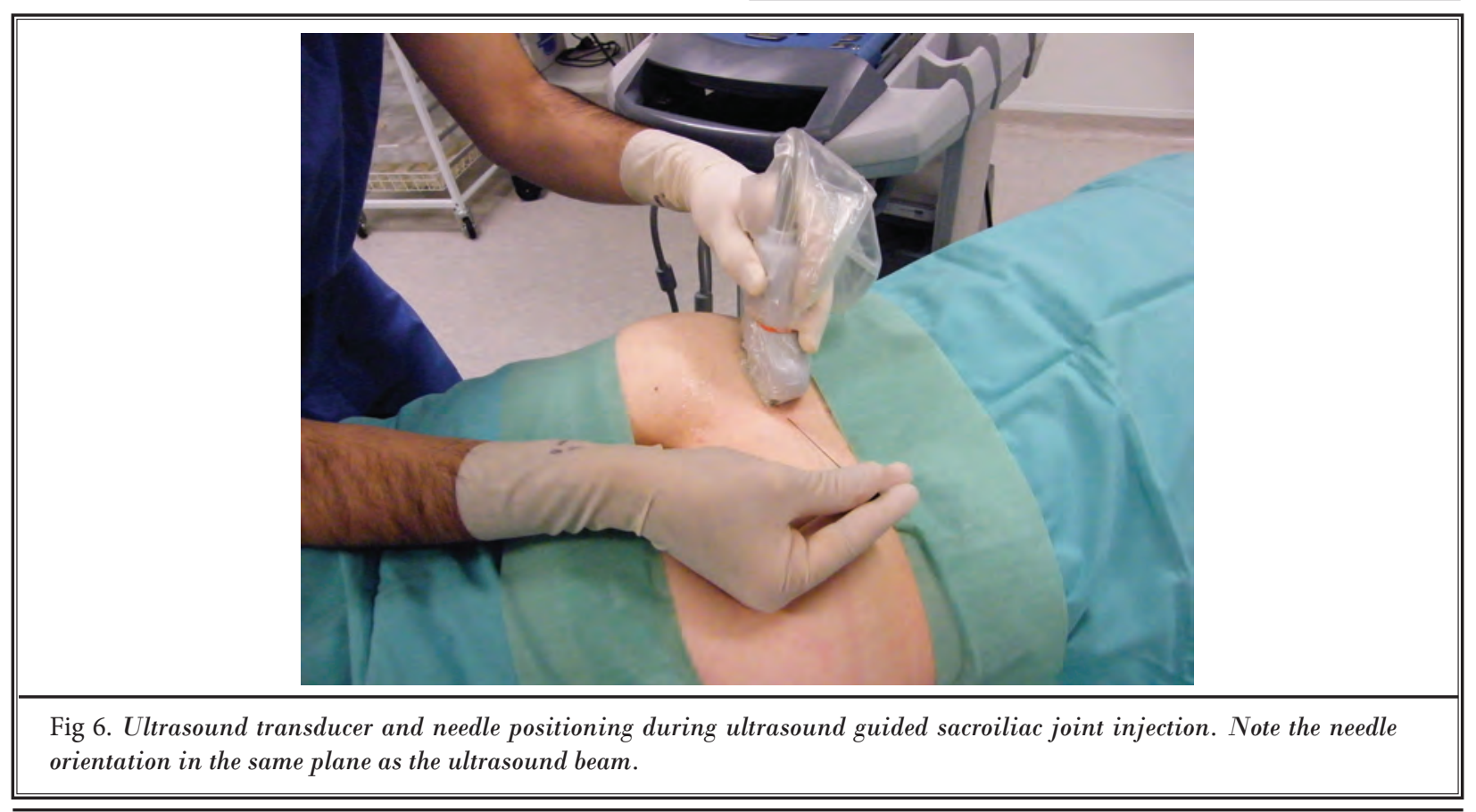




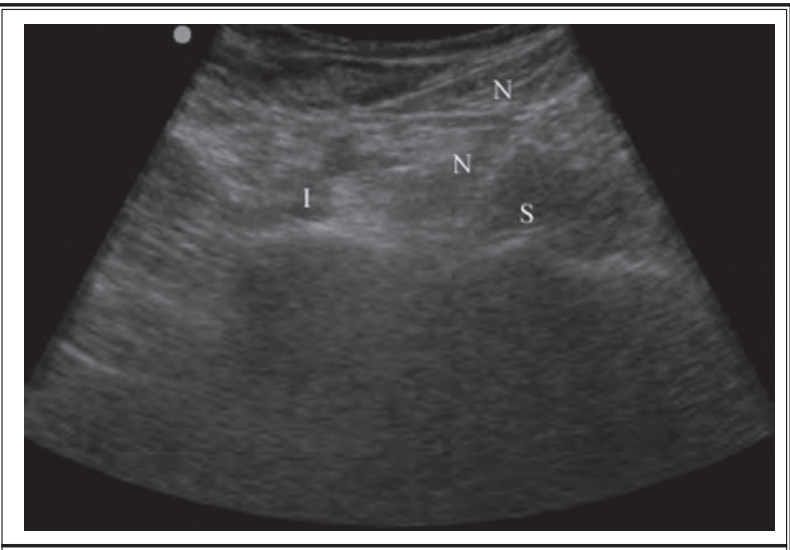

Fig. 7. Real-time imaging of needle insertion for the ultrasound guided sacroiliac joint injection. $I=$ ileum, $N=$ needle, $S=$ sacrum.

\section{Discussion}

Low back pain is a common and costly cause of disability. It is reported that the SIJ may contribute to pain in approximately $30 \%$ of patients with chronic low back pain and buttock pain $(2,3)$. The SIJ provides support, stability, and a mechanism for elasticity to the pelvis (4). Like other synovial joints, the SIJ is susceptible to arthritis, trauma, and degeneration, which leads to pain and dysfunction (2).

Initial treatment of low back pain, including SIJ pain, should include conservative measures of short-term bed rest, anti-inflammatory medications, and physical therapy (5). For those who fail to respond to conservative measures, benefit may be obtained from an interventional procedure. Therapeutic efficacy and favorable short- and long-term responses to image-guided intraarticular SIJ injections with fluoroscopy-, CT-, and MRIguided techniques have been reported (6-9).

SIJ injection can confirm a diagnosis of SIJ pain and be therapeutically beneficial $(10,11)$. Indeed, injection therapies play a major role in the treatment of various pain conditions and are becoming integral parts of the multidisciplinary therapies required to improve and rehabilitate patients with pain $(12,13)$.

The SIJ is difficult to enter with a needle because of its complex configuration. "Blind" injections are unreliable; Rosenberg and colleagues (14) showed that only $22 \%$ of SIJ injections done without imaging guidance were actually placed intraarticularly. Pekkafali and colleagues (15) investigated the feasibility and effectiveness of performing SIJ injections under sonographic guidance. They concluded that sonographically guided therapeutic injections to the SIJ could be a valuable alternative to other guidance modalities.

Studies are required to compare the technical aspects of ultrasound and fluoroscopy guided SIJ techniques. Ultrasound has advantages compared to fluoroscopy techniques. In pregnancy (patient or healthcare professional) radiation exposure is a concern. With the ultrasound, prone patient positioning is not required. Ultrasound portability allows procedures to be performed outside the operating room or regional anesthesia procedure room (e.g. hospital wards or nursing homes). Decreased cost associated with ultrasound is of benefit in developing countries.

Possible limitations for ultrasound guided SIJ injection include the potential for intravascular injection or limits with respect to dye flow and joint morphology. Ultrasound may have limitations in obese patients in the identification of soft tissue structures such as peripheral nerves (16). With interscalene brachial plexus blockade, obesity (BMI >25) was associated with a longer time to identify the brachial plexus by ultrasound $5 \pm 1 \mathrm{~min}$ versus $4 \pm 2 \mathrm{~min}$ (16). There was no difference in block success, however (16). In the ultrasound guided sacroiliac joint injection technique bony contours are identified. The use of ultrasound to detect bony contours is likely to be less influenced by obesity than the identification of nerves. Further studies should examine limitations of this technique. Comparative long-term clinical outcome studies are also required.

In this article, we describe a new technique of using real-time, high resolution ultrasound guidance to facilitate SIJ injection. We believe our technique to be more straight-forward and user-friendly than what is described by Pekkafali and colleagues (15). This allows for a shorter procedure time and a greater acceptance by both patient and physician.

Sacroiliac joint injections are commonly performed under either fluoroscopy or CT guidance. However, limitations associated with these techniques include exposure to ionizing radiation, the need for a contrast agent, and cost issues. These issues are particularly relevant in pain medicine where patients are likely to require repeated injections. The use of ultrasound-guided injections may be preferable in certain clinical scenarios. 


\section{References}

1. Laslett M, Young SB, Aprill CN, McDonald B. Diagnosing painful sacroiliac joints: $A$ validity study of a McKenzie evaluation and sacroiliac provocation tests. Aust J Physiother 2003; 49:89-97.

2. Schwarzer AC, Aprill CN, Bogduk N. The sacroiliac joint in chronic low back pain. Spine 1995; 20:31-37.

3. Waldmann SD. Interventional Pain Management, 2nd ed. Saunders, Philadelphia, PA, 2001; 535-539.

4. Harrison DE, Harrison DD, Troyanovich S). The sacroiliac joint: a review of anatomy and biomechanics with clinical implications. J Manipulative Physiol Ther 1997; 20:607-617.

5. van Tulder M, Koes B, Bouter L. Conservative treatment of acute and chronic non-specific low back pain. A systematic review of randomized controlled trials of the most common interventions. Spine 1997; 22:2128-2156.

6. Braun J, Bollow M, Seyrekbasan F, Häberle HJ, Eggens U, Mertz A, Distler A, Sieper J. Computed tomography guided corticosteroid injection of sac roiliac joint in patients with spondyloarthropathy with sacroiliitis: Clinical outcome and follow up by dynamic magnetic resonance imaging. I Rheumatol 1996; 23:659-664.
7. Silbergleit R, Mehta BA, Sanders WP, Talati SJ. Imaging-guided injection techniques with fluoroscopy and CT for spinal pain management. Radiographics 2001; 21:927-942.

8. Bollow M, Braun J, Taupitz M, Häberle J, Reibhauer BH, Paris S, Mutze S, Seyrekbasan F, Wolf KJ, Hamm B. CT-guided intraarticular corticosteroid injection into the sacroiliac joints in patients with spondyloarthropathy: Indication and follow-up contrast-enhanced MRI. J Comput Assist Tomogr 1996; 20:512521.

9. Pereira PL, Günayd NI, Trübenbach J, Dammann F, Remy CT, Kötter I, Schick F, Koenig CW, Claussen CD. Interventional MR imaging for injection of sacroiliac joints in patients with sacroiliitis. $A J R$ Am J Roentgenol 2000; 175:265-266.

10. Fortin JD, Dwyer AP, West S, Pier J. Sacroiliac joint: Pain referral maps upon applying a new injection/arthrography technique. Part 1: Asymptomatic volunteers. Spine 1994; 19:1475-1482.

11. Fortin JD, Dwyer AP, West S, Pier J. Sacroiliac joint: Pain referral maps upon applying a new injection/arthrography technique. Part 2: Clinical evaluation. Spine 1994; 19:1483-1489.
12. Kim PS. Role of injection therapy: Review of indications for trigger point in jections, regional blocks, facet joint in jections, and intra-articular injections. Curr Opin Rheumatol 2002; 14:52-57.

13. Carrino JA, Morrison WB, Parker L, Schweitzer ME, Levin DC, Sunshine JH. Spinal injection procedures: Volume, provider distribution, and reimbursement in the US Medicare population from 1993 to 1999. Radiology 2002; 225: 723-729.

14. Rosenberg JM, Quint TJ, de Rosayro AM. Computerized tomographic localization of clinically-guided sacroiliac joint injections. Clin J Pain 2000; 16:1821.

15. Pekkafahli MZ, Kiralp MZ, Ba Ekim CC, Silit E, Mutlu H, Oztürk E, Kizilkaya E, Dursun H. Sacroiliac joint injections performed with sonographic guidance. J Ultrasound Med 2003; 22:553-559.

16. Schwemmer U, Papenfuss T, Greim C, Brederlau J, Roewer N. Ultrasoundguided interscalene brachial plexus anaesthesia: Differences in success between patients of normal and excessive weight. Ultraschall Med 2006;27:245250. 